\title{
The Analysis of Constructing New Cultivation Mode for Male Undergraduate Preschool Teacher
}

\author{
Changmin Wang \\ Linyi University \\ Feixian, China
}

\begin{abstract}
In the field of preschool education, male teachers, a new emerging force, possess some peculiar educational values, which have aroused more and more attentions. With the deepening of preschool educational reforms, a growing number of males enter into the field of preschool education. Nevertheless, influenced by the traditional ideas, the cultivation mode for male undergraduate preschool teachers mostly follows females. Without its independent cultivation mode, the training and development of male preschool teachers' profession qualities has been limited. Thus, the problem of male preschool teachers' cultivation mode should be solved quickly. Guided by principles of Students Oriented and Teaching Based on Gender, it is the responsibilities of training institutions that setting goals on account of positive thinking, choosing content carefully, using methods properly, training male students' mentalities and abilities appropriately, forming their advantages, and cultivating the new mode for male undergraduate preschool teacher, etc.
\end{abstract}

Keywords-male preschool teacher; professional qualities; male student of preschool major; cultivation mode

\section{INTRODUCTION}

In the field of preschool education, male preschool teachers, the emerging forces, uniquely influence the education and development of children. Attentions are paid to male preschool teachers, especially their professional qualities, which refer to the decisive, internal and stable qualities of practitioners developed through educational training, professional practice and self-improvement, including professional consciousness, professional ethics and professional ability[1]. The investigation shows kindergarten principals and parents of children have high expectations for professional qualities of male preschool teachers, including moral quality, professional skills, psychological quality, specialties and gender traits. Preschool education and training units should train these qualities of male preschool teachers.

\section{PREDICAMENTS OF PRE-SERVICE CUltivation OF MALE PRESCHOOL TEACHERS AND REASONS}

\section{A. Predicaments in Cultivation}

The training of professional quality should conform to job expectancy of male preschool teacher, more importantly meet the requirements of kindergartens and parents and embody the demands of the time. At present, pre-service cultivation is beset with difficulties. First, the quantity of students is small and the quality is low. Difficulties exist in cultivating male preschool teachers. For example, although the branch school of Linyi University in Feixian County has no defect of sex in student enrollment and embraces male students in publicity, few male students choose preschool major, leading to low acceptance rate. This school recruited 183 and 137 college students of preschool education major and enrolled seven and nine male students in 2015 and 2016 respectively. Although the enrollment proportion rises slightly, the small quantity of male students becomes the primary difficulty in training male preschool teachers. Second, the career orientation isn't their real intention. Most male students enrolled in preschool education major don't follow their heart. Most of them don't take preschool teachers as their as professional ideal, so they break away from preschool education major through transferring to another school or dropping out or joining the army. For example, among eight male students enrolled by the branch school of Linyi University in Feixian County, two fail to register, one drops out and one joins the army soon after the beginning of the school. The unstable situation of male students in preschool education major influences their cultivation. Third, few male students in preschool education major have outstanding academic performance. Most male students enrolled in preschool education major fail to adapt to campus life, which influences their learning motivation. Besides, they have weak theoretical basis and difficulties in learning specialized skill courses. A total of 552 people in the branch school of Linyi University in Feixian County obtain school scholarship, National Encouragement Scholarship and National Scholarship during 2015 and 2015, among which include fifteen male students, accounting for about 2.7 percent of the total number. Obviously, male students' difficulties in learning influence the cultivation of male preschool teachers.

The above-mentioned difficulties lead to limited quantity of male preschool teachers, the professional quality of whom cannot reach the expectation of kindergarten principals and parents.

\section{B. Reason Analysis}

Why the above difficulties exist in cultivating male preschool teachers? First, it is the traditional professional idea. According to traditional social values, preschool teachers should be the profession of female. Low salary and social prejudice bring enormous professional pressure for male students in preschool education major who will not regard 
preschool teacher as their ideal job. Therefore, the quantity of male students in preschool major is low. Second, effective patterns of pre-service cultivation of male preschool teachers lack. Few male students are enrolled in preschool education major. The patterns and methods pre-service cultivation of male preschool teachers are almost equal to that of female ones. The gender differences are neglected. Male and female students learn dance, handwork and piano in the same class, which make male students embarrassed and influence their learning state. Third, it's gender predicament. Most male students cannot adapt to learning in the environment with female students in the majority. They are at sea even doubt themselves and have self-abasement. In this environment, male students are feminized and reduce masculinity. Four, they lack career planning. In pre-service cultivation, the lack of occupational guidance makes them fail to thoroughly understand their major and have unstable attitudes.

\section{Construction of New Patterns for Pre-Service Cultivation of Male Preschool Teachers}

Cultivating modes are implemented by school to achieve training objectives, including course structure, educational contents, educational technique and educational methods. It is the key to deepen teaching reform and decides the quality of talent training in universities[2]. When cultivating male preschool teachers, schools follow the traditional programs that train female preschool teachers, which go against the cultivation of male preschool teachers' professional expertise and gender traits including the professional qualities expected by kindergarten principals and parents. Therefore, preschool educators must think how to innovate in the pre-service cultivation mode of male preschool teachers.

\section{1) Adhere to the principle of education on people.}

Student orientation and teaching students in accordance of their aptitude are general principles of education, to which the cultivation of male preschool teachers must adhere. The student-oriented educational concept emphasizes all for students, highly respecting and depending on students[3]. In school of preschool education in which females are in the majority, the cultivation of male preschool teachers with masculinity must follow the principle that centers on male students' learning, life, development and employment and provides humanistic care for them, in order to realize free development. [4] Cultivation and professional development of male preschool teachers are respected. Teaching according to genders means acknowledging gender difference to teach. Education without gender difference is not suitable for male preschool teachers. Talent training should conform to students' sex character and requirements [5] to realize free development of students of different genders.

\section{2) Set training objectives.}

Talent training is inseparable from training objectives, the formulation of which must conform to social demands. To train what kind of male preschool teachers must be explicit. The objective should differ from that of female preschool teachers, which can be determined from three aspects.

First, male preschool teachers must be qualified and enthusiastic about education and have basic professional qualities of preschool teachers; second, they must be able to exert strengths of masculinity or have expertise in certain field, operational and creative ability, good psychological quality, healthy body and wholesome personality; third, they should be good professional teachers with scientific professional concept, noble moral sentiment, rich professional knowledge and strong practical ability as well as high quality. In short, the male preschool teachers must be qualified with expertise, optimistic and healthy.

\section{3) Optimize curriculum provision.}

In pre-service cultivation of male preschool teachers, curriculum provision should be optimized, in order to train their professional expertise. According to the training objectives of male preschool teachers, the innovation of course system enables them to choose courses independently and pertinently and better train specialty. Specifically speaking, it includes: (1) Optimize general education curriculum. Because male students are adept at rational thinking and operation, general education curriculums such as mathematics, physics, chemistry, computer and physical education can be provided and the class hour of English can be reduced, in order to conform to male students' characteristics. (2) Optimize courses of professional skills. The investigation indicates most male students in preschool education major are not interested in dancing because they feel embarrassed in having dance class. The dance class can be replaced by gym class. Similarly, if male students dislike manual training, audio and video producing can replace it. Courses difficult for students to learn can be adjusted to provide more learning opportunities for them and let them form professional skills. (3)Optimize professional elective courses. Courses such as computer maintenance, application and maintenance of audio-visual educational equipment can be provided for students in preschool education major; elective courses related to gym, martial art, chess and ball are provided to stimulate their thirst for knowledge and desire for exploration and train their professional qualities. Therefore, male students will exert strengths in teaching, IT application and management of kindergarten. The provision of professional elective courses should carry out mutual supplement of limited optional courses and unlimited optional courses, so that male students can choose different courses according to personal preference. Limited optional courses can relate to English, calligraphy, fine arts, computer, instrumental music and PE; unlimited optional courses relate to nursery teacher, Montessori education, infant education theories, kindergarten environment creation, coaching of Teacher Certification, musical education of Orff, vocal music performance and children dance.

\section{4) Innovate in teaching methods.}

The environment with female in the majority goes against the cultivation of masculinity. Male students of preschool education major will have pressure and will be "feminized" without timely adjustment. In rhythmic gymnastics class, male students should be provided with teaching contents and methods different from female students. For example, dance class and music class can be taught by male teachers, which help male students to build confidence in learning dance and vocal music and embody masculinity. In the course of professional teaching methods, educational styles must be 
provided for male students. Teachers should collect and display examples that male teachers practice in preschool education. Meanwhile, they must guide and evaluate according to genders, encourage male students to display their abilities, create boldly and embody masculinity.

The cultivation of male students in preschool education major can implement tutorial system: one professional teacher guides several students, so that they have more opportunities to communicate. The teacher can better lead male students and do psychological counseling and strengthen their ideological education [5].

\section{5) Shape healthy psychology.}

Kindergarten principals and parents require male preschool teachers to have healthy psychological quality, so the psychological health education must be strengthened. Because in the environment with female students in the majority, male students will have weak self-confidence, and it easily hurts their self-esteem and wavers their resolution in undertaking preschool education. Therefore, we must help male students of preschool education major to shape good psychological quality and release their mental stress and strengthen their selfadjustment ability.

(1) Educational activities are provided to create a normal, harmonious social and psychological environment for male students and let them understand the development history and prospect of preschool education. For example, introduce predecessors of preschool education such as Chen Heqin, Tao Xingzhi and Zhang Xuemen to them, in order to let them realize the importance of male in preschool education and strengthen their sense of career identity and improve professional belief[6].

(2) Guide them to carry out reasonable career planning and build correct occupational values. They understand psychological features of their own and the psychological qualities of excellent teachers such as loving heart, circumspection and patience. They are promoted to carry out self-supporting and self-shaping to meet requirements of preschool education, teach throughout their life and realize job expectancy.

\section{6) Improve practical abilities}

Practical abilities are indispensable for preschool teachers. The cultivation of male preschool teachers must solve the problem that male students have weak practical skills of preschool education. On one hand, teachers reform the traditional teaching methods according to male students' characteristics such as quick-wittedness, flexible action and creativity, respect their behaviors that break the routine and help them to overcome carelessness in learning and encourage them to use natural and concise teaching expressions, meanwhile, shouldn't urge them to do things that violate their characters or genders [7], so that they will form practical wisdom and ability. On the other hand, schools should cooperate with kindergartens and invite backbone teachers of preschool education and excellent managers to train male preschool teachers. Male students can practice in kindergartens to exercise practical and management abilities and improve self-confidence, laying foundation for future employment.

\section{7) Develop specialties.}

The cultivation of male preschool teachers must embody masculinity and their specialties expected by kindergarten principals and parents. Schools can develop specialties of male students of preschool education major such as martial art, running, rope skipping, ball games, computer maintenance, software application and technology of audio-visual education, and instrumental music related to guitar, saxophone and drum set, in order to strengthen their self-identification and core competitiveness. Teachers and teaching grounds should be provided by schools.

\section{CONCLUSION}

According to the general principles of "student orientation" and "teaching according to genders", in the pre-service cultivation mode of male preschool teachers including goal setting, content selection, method application, psychological shaping, ability training and strength exertion, more attentions should be paid to strength exertion, so that male students can build self-confidence, self-reliance and self-improvement and develop masculinity. They will be competent for physical education and game teaching in kindergartens and play roles in preschool education.

\section{REFERENCES}

[1] Fu Caihua, Wu Weiping. Analysis on Professional Qualities of Higher Vocational Medical Students and Training Countermeasures [J], Vocational and Technical Education Forum, 2010(17): 70-71

[2] Cao Li. Problems in Pre-service Education of Male Preschool Teachers and Construction of Characteristic Cultivating Mode: Investigation on Current Situation of Education for Male Students in Preschool Education Major in Local Normal Universities [J], Journal of Huaibei Coal Industry Teachers' College: Philosophy and Social Sciences, 2012(4): 133-134

[3] Zhang Jingle. Student Orientation, Potential Activation: Exploration on Ways of Improving Effectiveness of Chinese Writing Teaching [J], The Modern Education Journal, 2008(12): 85-86

[4] Zhong Hua. The Training of Male Preschool Teachers Must Be Studentoriented and Base on Gender [J], Journal of Ankang University, 2009(2): 114-116

[5] Zheng Hui. Thinking on Tutorial System Implemented in Higher Vocational Colleges [J], Journal of Xiangfan Vocational and Technical College, 2010(2): 98-100

[6] Xu Faxiu. Cultivation of Professional Sense of Identity of Male Preschool Teachers [J], Study on Educational Theory, 2012(8): 116-117

[7] Zhang Huanrong. Cultivation of Male Students in Preschool Education Major in Application-oriented Universities [J], Data of Culture and Education, 2010 (9): 184-185

[8] Zhang Huanrong. Cultivation of Professional Sense of Identity of Male Students in Preschool Education Major [J], The Science Education Article Collects, 2010(10): 9-10. 